\title{
Refractive surgery or contact lenses - how and when to decide?
}

This article was published in the following Dove Press journal:

Clinical Optometry

10 November 201 I

Number of times this article has been viewed

\author{
Kunyong $\mathrm{Xu}^{\prime}$ \\ Vishal Jhanji² \\ IMichael G DeGroote School of \\ Medicine, McMaster University, \\ Hamilton, Ontario, Canada; \\ ${ }^{2}$ Department of Ophthalmology \\ and Visual Sciences, The Chinese \\ University of Hong Kong, Hong Kong
}

Correspondence: Vishal Jhanji Department of Ophthalmology and Visual Sciences, The Chinese University of Hong Kong, Hong Kong

Tel +85227623180

Fax +852 27I5 9490

Email vishaljhanji@gmail.com
Abstract: Correction of refractive errors can be achieved with spectacles, contact lenses, and refractive surgery. The past decade has seen a surge in the availability of alternatives for patients and surgeons in terms of both surgical and nonsurgical options for the management of refractive errors. Newer generation contact lenses provide enhanced safety and better handling, whereas modern-day refractive surgery presents a plethora of choices based on the clinical characteristics and requirements of patients. We have moved from an era of "one size fits all" to a purely customized way of treating patients with refractive errors. This review presents the background, advantages, and disadvantages of the two most commonly used options for correction of ametropia, ie, contact lenses and refractive surgery.

Keywords: laser-assisted in situ keratomileusis, contact lens, patient selection, complications, outcomes

\section{Introduction}

The three main methods used for the correction of refractive errors are spectacles, contact lenses, and refractory surgery. The decision to choose one of these modalities is based on multiple factors, including availability, benefits, and the potential complications associated with a particular method. Over the past decade, contact lenses and refractive surgery have emerged as attractive options for people with refractive errors. We review the background, indications, and rationale behind choosing one of the contemporary methods used for correction of ametropia.

\section{Contact lenses}

Contact lenses act as optical media resting on the surface of the cornea. Based on the material they are composed of, they can be hard, soft, or rigid gas-permeable lenses. During the early phase of development, plaster of Paris was used for manufacturing contact lenses. ${ }^{1}$ In 1936, polymethylmethacrylate was used as a contact lens material, which gave way to the development of poly-2-hydroxyethyl methacrylate in the $1960 \mathrm{~s}^{2}$ It was soon discovered that hydroxyethyl methacrylate had low oxygen permeability and was not suitable for overnight or extended wear. The 1980s witnessed the development of polydimethyl siloxane as a contact lens material. Although its oxygen permeability is extremely high, polydimethyl siloxane has a high affinity for lipids and consequently requires surface treatment. ${ }^{3}$ Silicone hydrogel lenses are the latest generation of contact lens materials. The lens has high oxygen transmissibility, and sufficient hydrophilicity. ${ }^{2}$ The current market movement towards the continuous wear 
of silicone hydrogel lenses is probably due to patient convenience in addition to the superior comfort provided by these contact lenses.

With the technologic advances in contact lens materials and manufacturing, different types of contact lenses could be chosen to fit a patient's personal preference and lens-wearing schedule. Patients could choose to wear contact lenses for a day, a week, or a month. In addition, patients may wear lenses only while awake, or may keep the lenses in while sleeping for a few nights a week or for an entire week, depending on lens type and the practitioner's recommendation.

\section{Rigid gas-permeable lenses}

Rigid gas-permeable lenses are used to correct myopia, hyperopia, or astigmatism. They are also used as specialty lenses for patients with keratoconus and irregular corneas. A rigid gas-permeable contact lens with multiple posterior curvatures to flatten the anterior corneal curvature has been utilized for overnight corneal reshaping or orthokeratology. These lenses have a "reverse geometry" design with a central curvature that is flatter than the peripheral curves. In June 2002, Paragon CRT (Paragon Vision Sciences, Mesa, AZ) was approved by the United States Food and Drug Administration (FDA) to be worn overnight for temporary correction of myopia up to $6.00 \mathrm{D}$ and less than $1.75 \mathrm{D}$ of astigmatism. ${ }^{4}$ Later, vision-shaping treatment (Bausch and Lomb/Euclid 2004) was also approved by the FDA to be used for up to $5.00 \mathrm{D}$ of myopia and 1.50 D or less of astigmatism. ${ }^{5}$ It takes $7-10$ nights wearing the lenses to obtain an optimal effect. Generally, most patients wear the lenses every night, although some patients find that they can skip nights occasionally and still retain consistent good vision.

\section{Conventional soft lenses}

Conventional soft lenses are cleaned, disinfected, and/or enzymed on a daily basis. One pair of conventional soft lenses lasts for about a year. Currently, these lenses are rarely used because of the lowered costs and convenience of planned replacement lenses.

\section{Daily disposable lenses}

Daily disposable contact lenses are discarded after single use. The main advantage is near-zero maintenance. However, the associated cost is high. Although the risk of microbial keratitis is not reduced in daily disposable and silicone hydrogel contact lenses users, vision loss is less likely to occur in daily disposable than in reusable soft contact lens users. ${ }^{6}$

\section{Planned replacement lenses}

Planned replacement lenses are used daily and usually replaced after 2 weeks, 1 month, or 3 months. They should be rinsed with cleaning solution, and stored in a contact lens case on a daily basis. Although they need more care than the disposable lenses, they are very popular amongst the general population.

\section{Extended-wear lenses}

Extended-wear lenses permit adequate oxygen transmissibility to the cornea so that there is minimal corneal edema with continuous use. These lenses can be used for a couple of days in a row, followed by a break. These lenses usually come in monthly disposable packs. More importantly, these lenses are deemed suitable for overnight wear.

\section{Toric lenses}

Toric lenses are capable of providing good vision in patients with astigmatic refractive errors. These lenses can be conventional yearly lenses or planned replacement lenses that need to be discarded on a regular basis.

\section{Bifocal lenses}

Bifocal lenses are available as either soft or rigid gaspermeable lenses with varied disposable schedules. The lenses provide good vision and comfort and can be used as an alternative for patients who do not want to use glasses with near-add.

\section{Refractive surgery}

Refractive corneal surgery quickly progressed from radial keratotomy in the 1980 s to photorefractive keratectomy and laser in situ keratomileusis (LASIK) in the 1990s. Currently, LASIK is the most popular corneal refractive technique to correct myopia, hyperopia, or astigmatism. All the above mentioned procedures have a common goal, ie, to change the refractive error of the eye by altering the shape of the corneal surface. The alteration in corneal curvature is achieved by controlled application of the excimer laser in a process termed photoablation. During surface ablation, the anterior corneal stroma is photoablated. However, in LASIK, photoablation is directed to a region within the corneal stroma.

\section{Radial keratotomy}

Radial keratotomy involves the use of a diamond blade to create radial incisions in the periphery of the cornea. The incisions flatten the central cornea. The new shape of the 
cornea is retained as the cornea heals. radial keratotomy has been used to treat patients with myopia and astigmatism. The popularity of this procedure has declined over the years due to better results from other commonly performed refractive surgeries. Radial keratotomy weakens the cornea, and the potential complications of the surgery include loss of best-corrected vision acuity, infection, and rupture of the globe..$^{7-9}$ Radial keratotomy may also induce corneal instability and induce diurnal fluctuation of refractive error and hyperopic shift. ${ }^{10}$

\section{Photorefractive keratectomy}

Photorefractive keratectomy is a two-step procedure for the correction of ametropia. The corneal epithelium in the ablation zone is first scraped off to allow ablation of corneal tissue. Then the excimer laser is applied to the exposed corneal stroma to change the shape of the cornea. ${ }^{11}$ The excimer laser produces an ultraviolet beam to break the intermolecular bonds within the cornea. A computer, programmed with the patient's refraction and corneal topography, controls the laser beam to remove the corneal tissue precisely. ${ }^{12}$ In myopia, the laser flattens the central cornea to decrease its focusing power. In hyperopia, the laser removes the tissue periphery and indirectly steepens the central cornea to increase the focusing power of the cornea. For astigmatism, an elliptic or cylindrical beam is used to flatten the steepest corneal meridian.

Photorefractive keratectomy effectively treats patients with low, moderate, or high myopia, myopia with astigmatism, and low-to-moderate hyperopia without astigmatism. ${ }^{11,13-17}$ The most common intraoperative complications of photorefractive keratectomy include decentration of the laser ablation and central islands of higher refractive power. ${ }^{11,18,19}$ The postoperative complications include pain secondary to an epithelial defect and/or delayed epithelial healing, an increase in the risk of infection, as well as late haze formation and corneal scarring. ${ }^{19}$

\section{LASIK}

Currently, laser-assisted in situ keratomileusis is the most commonly performed refractive surgery. With an average minimal central corneal thickness of about $520 \mu \mathrm{m}$, a corneal flap of 120-180 $\mu \mathrm{m}$ thickness is cut either by an oscillating blade (microkeratome) or by a femtosecond laser (Nd:YLF laser, $\lambda=1053 \mathrm{~nm}) .{ }^{20}$ This flap is then folded back to expose the underlying stroma and to allow the excimer laser to reshape the corneal stroma. ${ }^{21-23}$ The flap is then replaced to its original position. ${ }^{24}$ The femtosecond laser is a solid-state laser that yields planar flaps and epithelial injury is minimized. ${ }^{25,26}$ Unlike photorefractive keratectomy, there is minimal disturbance to the surface epithelium during LASIK. Consequently, there is minimal postoperative discomfort, little stimulus for scar formation, and rapid visual recovery when compared with surface treatment.

\section{LASEK and epiLASIK}

In laser-assisted subepithelial keratectomy (LASEK) and epiLASIK, the epithelium of cornea is reflected intact as a sheet following a brief application of dilute ethyl alcohol or mechanical stripping, after which the epithelial flap can be replaced or discarded. ${ }^{27}$ LASEK aims to improve the postoperative healing process and could be used as an alternative surgical treatment for patients with thin corneas. ${ }^{28}$ Although earlier reports showed an inconsistent postoperative visual recovery and pain profile for LASEK, ${ }^{29}$ recent studies have confirmed good refractive outcomes for patients with mild to high myopia. ${ }^{30-32}$

EpiLASIK works on the same concept as LASEK except that it uses a microkeratome to create an epithelial flap. An epikeratome, a device similar to the microkeratome used in LASIK, creates a corneal flap at the level of the basement membrane, sparing the stromal bed and maintaining the integrity of the basement membrane. Although a study of epiLASIK showed that $53 \%$ patients had uncorrected visual acuity of $20 / 40$ or better on postoperative day 1 , which increased to $78 \%$ with corneal epithelialization on days $3-7,{ }^{33}$ the superiority of epiLASIK compared with other surface ablation techniques is not clear.

\section{Contact lenses versus laser vision correction surgery}

Both contact lenses and refractive surgery have shown an active growth over a long time. It has become increasingly useful for health practitioners in routine optometric practice to be aware of patient motivations for contact lenses and/or refractive surgery. ${ }^{34}$

Some individuals prefer nonsurgical methods to correct their vision and will only consider contact lenses or spectacles. Others, who do not wish to rely on contact lenses or spectacles, may prefer a more permanent solution to correct their refractive errors. In addition, some people may change from one method to the other. They might first try contact lenses, then consider refractive surgery as they become older, or when they begin to experience discomfort or problems associated with contact lens use. 


\section{OCR lenses}

\section{Candidates}

Low myopes who cannot tolerate contact lens, are not suitable for LASIK, or have residual refractive error after LASIK, are good candidates for overnight corneal reshaping (OCR). ${ }^{35-39}$ Dry eye syndrome is a common complaint among contact lens wearers and is one reason some patients seek LASIK or OCR. However, patients with severe dry eyes may not be candidates for either procedure. Contact lens wearers bothered by allergy-related itching are also good candidates for OCR. ${ }^{40}$

\section{Efficacy}

A study that followed 23 patients using OCR for 4 weeks showed that unaided visual acuity improved to $0.00 \log$ MAR by day 4 and remained consistent throughout waking hours by day $10 .{ }^{41}$ In addition, unaided acuity and refractive error remained consistent through day 28. Another study that followed 29 children aged 8-11 years for 6 months of corneal refractive therapy found that uncorrected acuity was $0.08 \pm 0.15 \log$ MAR at the 6-month visit. ${ }^{35}$ Similar results have been demonstrated using three different lens designs to evaluate long-term effectiveness of overnight orthokeratology. ${ }^{36}$ The return to baseline myopia after discontinuation of corneal reshaping lenses has also been assessed. ${ }^{37,38}$ Most recovery occurs within 72 hours after discontinuation of lens wear. Higher myopic corrections regressed more quickly. ${ }^{37,38}$ In uncontrolled studies, OCR induced higher-order corneal aberrations after lens removal. $^{39,42}$ This contributed to a decrease in low-contrast corrected visual acuity. ${ }^{39,42}$

\section{Complications}

Microbial keratitis is an important safety issue for patients using OCR. ${ }^{43}$ The most significant findings were positive culture for Pseudomonas aeruginosa (52\%) and Acanthamoeba (30\%). ${ }^{43}$ Positive culture of Acanthamoeba raises concern because of the difficult treatment, prolonged course, and poor outcomes in these cases. ${ }^{44}$ This group of organisms has been confirmed in more recent reports. ${ }^{45-49}$ The highest prevalence is among children aged 9-15 years, which accounts for up to $61 \%$ of cases. ${ }^{43,49}$ It is not clear whether the predilection of infectious keratitis for young Asian OCR patients is associated with the patterns of OCR use in Asia or with other factors. The OCR procedure is effective and there are fewer symptoms and a decrease in slit-lamp findings over time. ${ }^{36}$ However, there is little quantitative information available to examine long-term safety in a large number of patients.
Extended-wear lenses may not offer any protection from infection by regular cleaning and disinfection. ${ }^{50,51}$ However, the increased oxygen transmissibility of silicone hydrogel material reduces corneal hypoxia and diminishes tissue damage. Thus, there is reduced bacterial binding to corneal epithelial cells and possibly a decrease in risk of development of microbial keratitis. ${ }^{50,52}$

\section{Attitudes/Quality of life}

A crossover study, which assessed patients who wore both corneal reshaping lenses and soft disposable lenses for 2 months, showed that $67 \%$ chose the corneal reshaping lenses as their preferred mode of correction. ${ }^{53}$ This study evaluated vision-related quality of life attributes using the National Eye Institute Refractive Error Quality of Life (NEIRQL) 42, and showed that there was no significant difference in perceived acuity with soft lenses compared with OCR lenses. Another study used the NEI-RQL 42 to compare OCR patients with LASIK patients. ${ }^{54}$ No significant vision-related quality of life differences were found in the two groups by the end of the study, although there were differences noted in the two groups prior to treatment.

\section{Contact lenses other than rigid gas-permeable Candidates}

The use of contact lenses for visual, therapeutic, and cosmetic reasons has increased over the last few years and is highest among young adults. ${ }^{55,56}$

\section{Complications}

Complications of regular contact lens use can occur with all lens types despite improvement in the materials used. ${ }^{57-59}$ The most common complications include giant papillary conjunctivitis, corneal abrasions, microbial keratitis, neovascularization, and peripheral infiltrates. ${ }^{56,59}$ In addition, allergic conjunctivitis and dry eye may cause discomfort and possible contact lens dropout.

It is well established that the use of contact lenses may result in changes of corneal surface shape and physiology. ${ }^{60-62}$ In 1965, Hartstein first used the term "corneal warpage" to explain contact lens-induced corneal changes in patients who wore polymethylmethacrylate contact lenses. ${ }^{63}$ Warpage may result from the mechanical effect of the lens on the cornea and/or contact lens interference with corneal metabolism. ${ }^{61}$ Different studies have shown that corneal warpage may also occur among patients using soft contact lenses..$^{62,64}$ 
Another consequence of contact lens wear that may affect eligibility for refractive surgery is changes in corneal thickness. Results of different studies suggest that contact lens wear increases corneal thickness during the early period, then decreases it after "prolonged" use. ${ }^{60,65,66}$ The effects of contact lenses on corneal physiology include hypoxic changes, epithelial edema, stromal swelling, and polymegathism of the corneal endothelium. ${ }^{67}$ With cessation of contact lens wear, epithelial edema subsides within days. ${ }^{67}$

\section{Attitudes}

One study showed that patients opting for refractory surgery were significantly younger when compared with those who opted for contact lenses. ${ }^{68}$ Further, there were significant differences in occupational profile between the groups. Primary motivations for choosing refractory surgery or contact lenses were cosmesis and the inconvenience associated with contact lens and spectacle use. ${ }^{68}$ It was further shown that choice of an optometrist/physician was based on the reputation of respective centers. ${ }^{68}$ If the general cosmetic effects of refractive surgery and contact lenses are considered, the former is seen as a more permanent approach and achieves the same cosmetic end result ${ }^{68}$ In another study, the inconvenience associated with contact lens use was overwhelmingly the most popular motivation for patients not opting for contact lenses. ${ }^{69}$ This indicates that despite the availability of daily disposable and continuous wear lenses, together with simpler cleaning systems for monthly disposable lenses, many find these to be inconvenient. This may be related to issues concerning interference with patient lifestyle. However, with the advent of silicone hydrogel lenses that allow for improved corneal physiology and longer wearing, this finding may pose a question regarding appropriate contact lens management by practitioners. ${ }^{68}$

\section{LASIK}

\section{Candidates}

LASIK has become the most popular method in most corneal refractive surgery practices. It has been used in patients with low, moderate, and high myopia with or without astigmatism, as well as hyperopia with or without astigmatism. ${ }^{23,70-74}$ However, in active people who are prone to trauma, such as those in the military or those involved in contact sports, potential problems with flap stability can lead to flap dislocation with trauma. Moreover, patients with thin corneas may not be suitable for LASIK due to the risk of iatrogenic keratectasia. Surface ablation, such as photorefractive keratectomy, LASEK, and epiLASIK, is often the preferred procedure in these settings as well as in patients with moderately dry eyes. ${ }^{75}$

\section{Efficacy}

The amount of refractive error that can be corrected by laser is determined by the curvature and thickness of the cornea. ${ }^{75}$ If the cornea is steepened or flattened excessively, the image quality may be degraded, and the cornea can be structurally weakened. Cases with high refractive error and a wide treatment diameter have a larger amount of tissue removed when compared with smaller treatment zones and low refractive errors. ${ }^{76}$ The desired residual stromal thickness after LASIK is at least $250 \mu \mathrm{m}$, which approximately equates to a maximum treatment of about $-10 \mathrm{D}$ of myopia. ${ }^{77} \mathrm{~A}$ loss of best-corrected visual acuity and tear film instability are associated with a correction greater than $+6.0 \mathrm{D}$ of hyperopia. ${ }^{77}$ The principal difference between surface treatment (photorefractive keratectomy, LASEK, and epiLASIK) and LASIK is the speed of visual recovery and the discomfort associated with the procedure. ${ }^{77}$ Despite the different surgical techniques of photorefractive keratectomy and LASIK, the refractive outcomes have been shown to be similar. ${ }^{13,16,78,79}$

\section{Outcomes of refractive surgery}

The goal of laser vision correction surgery is to achieve functional vision so that the patient is able to perform daily tasks such as driving, work, or recreation without feeling visually restricted. ${ }^{77} \mathrm{~A}$ general guideline for outcome is that $90 \%$ of patients will experience a $90 \%$ reduction in their refractive error. ${ }^{80}$ Presbyopic patients (more than 45 years) must understand that they will still have to wear glasses for reading. However, by leaving one eye slightly myopic (usually the nondominant eye), it is possible to reduce the dependence on reading glasses and achieve monovision. Retrospective studies of monovision in refractive surgery patients have reported success rates of $80 \%-90 \%,{ }^{81} 88 \%,{ }^{82} 92.5 \%,{ }^{83}$ $96 \%,{ }^{84}$ and $98 \% .{ }^{85}$ However, reduced contrast sensitivity ${ }^{86}$ and reduced stereopsis ${ }^{86,87}$ are the two major disadvantages of monovision.

\section{Complications}

Intraoperative flap complications that occur with the use of the microkeratome include incomplete flaps, irregular flaps, small flaps, flap decentration, buttonhole flaps, or free cap flaps. ${ }^{24,88,89}$ Postoperative complications include dislodging of the flap, flap striae, interface debris, epithelial downgrowth, and diffuse lamellar keratitis..$^{24,90,91}$ Posterior segment complications, such as posterior vitreous detachment, ${ }^{92-94}$ 
rhegmatogenous retinal detachment, ${ }^{95}$ and macular hole $e^{96,97}$ have been reported after LASIK.

A study of patients with ocular complaints who had LASIK, photorefractive keratectomy, radial keratotomy, or laser thermokeratoplasty showed that the most common subjective complaints were blurred distance vision (59.0\%), glare and night vision disturbances $(43.5 \%)$, and dry eyes $(21.1 \%) .{ }^{98}$ The most common complications were overcorrection $(30.4 \%)$, irregular astigmatism (29.8\%), dry eyes $(29.8 \%)$, glare $(26.1 \%)$, difficulty with night driving (16.7\%), and corneal haze (16.7\%). Qualitative visual disturbances, such as glare, halos, difficulty with night driving, ghosting, and shadows, can be a result of residual refractive errors or irregular astigmatism related to decentered ablation and deeper myopic and/or astigmatic ablations, at times in association with larger pupil size in mesopic conditions. ${ }^{99-101}$

Induction of irregular astigmatism and keratectasia is a serious but often under-reported complication following refractive surgery. ${ }^{102}$ Such incidents can often be prevented with careful preoperative screening. Corneal ectasia is vision-threatening and is a leading cause of litigation. ${ }^{103,104}$ Pre-existing forme fruste keratoconus, greater ablation depth, thin residual stromal bed thickness, and multiple postoperative enhancements are associated with post-LASIK estasia. ${ }^{105}$ Post-LASIK ectasia is also accompanied by noninflammatory stromal thinning in the residual bed and flap. ${ }^{106}$ The lamellar corneal cut and subsequent excimer laser ablation lead to a biomechanical instability which is unable to support the continuous stresses caused by intraocular pressure, blinking, eye rubbing, and other forces. ${ }^{107}$ Management options are limited once keratectasia sets in. Contact lenses (soft and rigid gas-permeable) are a common palliative treatment if tolerable and if spectacle correction is unsatisfactory. ${ }^{108-110}$

Refractive surgery, especially LASIK, changes the biomechanics of the cornea. ${ }^{111}$ Corneal biomechanical properties can be measured by the ocular response analyzer (ORA). The ORA measures corneal hysteresis and the corneal resistance factor. It is postulated that corneal hysteresis is a measure of viscous damping in the corneal tissue or the energy absorption capability of the cornea, whereas the corneal resistance factor is a measure of the cumulative effects of both viscous damping and elastic resistance of the cornea. Previous studies have found that higher attempted corrections correlate with greater reductions in corneal hysteresis and corneal resistance factor parameters. ${ }^{12,113}$ However, it remains to be seen whether low preoperative corneal hysteresis and corneal resistance factor values are important in estimating the risk for poor outcomes, especially keratectasia, in a patient presenting for refractive surgery. Further, it has been stated that although surface ablation (photorefractive keratectomy) and LASIK can affect the biomechanical strength of the cornea, the extent of biomechanical changes is larger after LASIK than after photorefractive keratectomy. ${ }^{114}$

In parallel with the development of LASIK, there have been improvements in the techniques of surface treatment, notably, introduction of the topical antimetabolite, mitomycin C, that is applied to the wound for 10-60 seconds after surface treatment to inhibit the scarring response. A recent meta-analysis suggests that topical intraoperative application of mitomycin C $0.02 \%$ reduces haze and improves visual acuity after surface ablation for correction of myopia. ${ }^{15}$ The range of refractive errors treatable by surface treatment or LASIK is now similar.

\section{Correction of refractory error for children}

Spectacles and contact lenses remain the most common methods for treating pediatric refractive errors and associated amblyopia. When tolerated, spectacles work very well and protect the eyes from injury. Children may not tolerate spectacles for a variety of reasons, including social stigma, a narrowed field of view, and prismatic aberrations in high ametropia. ${ }^{116}$ Contact lenses can alleviate some of these problems but have their own associated challenges and risks, including difficulty with insertion and removal, infection, intolerance to extended wear, and expense. ${ }^{116}$ Some pediatric patients do not tolerate spectacles or contact lenses owing to neurobehavioral disorders. Patients with craniofacial and ear abnormalities cannot wear glasses, and may not tolerate contact lenses. Therefore, refractive surgery may be required in special subpopulations of children. ${ }^{117}$ Difficult issues in this age group include the need for anesthesia, lack of pediatric nomograms, instability of refractive error, and susceptibility to trauma. ${ }^{116}$ In addition, refractive surgery alone does not treat associated amblyopia, and continued noncompliance with occlusion therapy can limit possible surgical outcomes. ${ }^{118}$

Brown notes that patients with the clearest indication for refractive surgery, ie, high unilateral myopia with amblyopia, also have the highest risk of long-term complications. ${ }^{119}$ Nassaralla and Nassarralla reported LASIK outcomes in nine children aged $8-15$ years. ${ }^{120}$ The authors reported that LASIK was a safe and effective option for the correction of high anisometropia and for improved 
binocularity. O'Keefe and Nolan reported encouraging results in six children with high myopia from -5.00 to -16 D. ${ }^{121}$

One of the problems associated with refractive surgery in the pediatric age group is the need for enhancement. Philips et al showed that in bilateral hyperopic patients, the mean undercorrection rate was $34 \%$, and $47 \%$ of patients required LASIK enhancement. ${ }^{122}$

Generally, consensus exists in the literature on several issues. ${ }^{123}$ It is understood that precision results achieved in adult refractive surgery may not be possible in children. Potential indications for pediatric refractive surgery include neurodevelopmentally abnormal patients failing traditional treatment and neurodevelopmentally normal patients with a high risk of amblyopia. ${ }^{116}$ The choice of refractive procedure depends on the clinical situation and surgeon preference. LASIK advocates argue that photorefractive keratectomy carries a high risk of haze and myopic regression. Photorefractive keratectomy may require long-term steroid use with concomitant risk of cataracts and glaucoma. In contrast, photorefractive keratectomy advocates argue that the risk of LASIK flap dislocation in children who are prone to eye rubbing and trauma outweighs the risks posed by photorefractive keratectomy. In a recent meta-analysis by Alio et al, data were included from 213 amblyopic eyes in patients aged $1-17$ years and undergoing photorefractive keratectomy, LASEK, or LASIK. ${ }^{124}$ A significant increase in uncorrected $\log$ MAR as well as corrected distance visual acuity was found in the overall sample after surgery. The change in uncorrected distance visual acuity was significantly superior for eyes undergoing surface ablation compared with those undergoing LASIK. Corneal haze was reported in $5.3 \%$ of LASIK cases and $8.5 \%$ of surface ablation cases. With improvements in anesthesia protocol and laser technology, it is likely that younger children will undergo refractive surgery and more definitive evidence will emerge.

\section{Conclusion}

Studies have suggested that there may be a relationship between myopia and psychological traits, such as distress, low self-esteem, and high intelligence. ${ }^{125,126}$ These factors may be involved in decision-making for selection of refractive surgery and/or contact lenses. Furthermore, access to refractive surgery has become more widespread and patients are now presented with a number of options when deciding on a provider. ${ }^{127}$

Important developments in the areas of refractive surgery have facilitated its growth. Improvements in microkeratomes, introduction of new laser platforms, and refractive procedures have resulted in expanded parameters, improved results, and a decrease in the incidence of complications. Future advances will result in maximizing patient outcomes with better predictability and even fewer complications. Current published statistics on LASIK report that $85 \%-100 \%$ of patients achieve $20 / 40$ vision but only $65 \%-80 \%$ achieve an unaided visual acuity of 20/20. ${ }^{128,129}$ Thus, many patients may still need glasses or even contact lenses for a specific visual task, such as driving at night. Clearly, there is no one method for correction of refractive error that is most appropriate or appealing to all patients. Patients make the choice of correction based on the cost, convenience, benefits, risks or complications, and long-term stability of the different options. Guidance from health care professionals could be most useful in order to help patients make an informed decision.

\section{Disclosure}

The authors report no conflicts of interest in this work.

\section{References}

1. Pearson R. Karl Otto Himmler, manufacturer of the first contact lens. Cont Lens Anterior Eye. 2007;30(1):11-16.

2. Nicolson PC, Vogt J. Soft contact lens polymers: an evolution. Biomaterials. 2001;22(24):3273-3282.

3. Kunzler JF. Silicone hydrogels for contact lens application. TRIP. 1996;4:52-59.

4. Paragon Vision Sciences. Premarket approval application supplement \#P870024/S43. Jun 2002. Available from: http://www.accessdata fda.gov/cdrh_docs/pdf/P870024S043b.pdf. Accessed October 25, 2011.

5. Bausch \& Lomb/Euclid. Premarket approval application \#P010062/S001/ S002. Jun 2004. Available from: http://www.fda.gov/MedicalDevices/ ProductsandMedicalProcedures/DeviceApprovalsandClearances/ PMAApprovals/ucm110901.htm. Accessed October 25, 2011.

6. Dart JK, Radford CF, Minassian D, Verma S, Stapleton F. Risk factors for microbial keratitis with contemporary contact lenses: a case-control study. Ophthalmology. 2008;115(10):1647-1654.

7. Kugler LJ, Hill S, Sztipanovits D, Boerman H, Swartz TS, Wang MX. Corneal melt of incisions overlying corneal ring segments: case series and literature review. Cornea. 2011;30(9):968-971.

8. Mimura T, Fujimura S, Yamagami S, et al. Severe hyperopic shift and irregular astigmatism after radial keratotomy. Eye Contact Lens. 2009;35(6):345-347.

9. Levy J, Hirsh A, Klemperer I, Lifshitz T. Late-onset Pseudomonas keratitis after radial keratotomy and subsequent laser in situ keratomileusis: case report and literature review. Can J Ophthalmol. 2005;40(2):211-213.

10. Ren DH, Yamamoto K, Ladage PM, et al. Adaptive effects of 30-night wear of hyper-O(2) transmissible contact lenses on bacterial binding and corneal epithelium: a 1-year clinical trial. Ophthalmology. 2002;109(1):27-39.

11. Seiler T, McDonnell PJ. Excimer laser photorefractive keratectomy. Surv Ophthalmol. 1995;40(2):89-118.

12. Alessio G, Boscia F, La Tegola MG, Sborgia C. Topography-driven photorefractive keratectomy: results of corneal interactive programmed topographic ablation software. Ophthalmology. 2000;107(8): $1578-1587$. 
13. Hersch PS, Brint SF, Maloney RK, et al. Photorefractive keratectomy versus laser in situ keratomileusis for moderate to high myopia. A randomized prospective study. Ophthalmology. 1998;105(8): 1512-1523.

14. McDonald MB, Deitz MR, Frantz JM, et al. Photorefractive keratectomy for low-to-moderate myopia and astigmatism with a small-beam, tracker-directed excimer laser. Ophthalmology. 1999;106(8): 1481-1488.

15. Carones F, Gobbi PG, Vigo L, Brancato R. Photorefractive keratectomy for hyperopia: long-term nonlinear and vector analysis of refractive outcome. Ophthalmology. 1999;106(10):1976-1983.

16. Pop M, Payette Y. Photorefractive keratectomy versus laser in situ keratomileusis: a control-matched study. Ophthalmology. 2000;107(2): 251-257.

17. Hersch PS, Stulting RD, Steiner RF, et al. Results of phase III excimer laser photorefractive keratectomy for myopia. The Summit PRK Study Group. Ophthalmology. 1997;104(10):1535-1553.

18. Krueger RR, Saedy NF, McDonnell PJ. Clinical analysis of steep central islands after excimer laser photorefractive keratectomy. Arch Ophthalmol. 1996;114(4):377-381.

19. Alio JL, Artola A, Claramonte PJ, Ayala MJ, Sanchez SP. Complications of photorefractive keratectomy for myopia: two year follow-up of 3000 cases. J Cataract Refract Surg. 1998;24(5):619-626.

20. Kurtz RM, Horvath C, Liu HH, et al. Lamellar refractive surgery with scanned intrastromal picosecond and femtosecond laser pulses in animal eyes. J Refract Surg. 1998;14(5):541-548.

21. Pallikaris IG, Papatzanaki ME, Stathi EZ, Frenschock O, Georgiadis A. Laser in situ keratomileusis. Lasers Surg Med. 1990;10(5):463-468.

22. Buratto L, Ferrari M, Genisi C. Myopic keratomileusis with the excimer laser: one-year follow up. Refract Corneal Surg. 1993;9(1):12-19.

23. Yoo SH, Azar DT. Laser in situ keratomileusis for the treatment of myopia. Int Ophthalmol Clin. 1999;39(1):37-44.

24. Gimbel HV, Penno EE, van Westenbrugge JA, Ferensowicz M, Furlong MT. Incidence and management of intraoperative and early postoperative complications in 1000 consecutive laser in situ keratomileusis cases. Ophthalmology. 1998;105(10):1839-1848.

25. Kezirian GM, Stonecipher KG. Comparison of the IntraLase femtosecond laser and mechanical keratomes for laser in situ keratomileusis. J Cataract Refract Surg. 2004;30(4):804-811.

26. Binder PS. Flap dimensions created with the IntraLase FS laser. J Cataract Refract Surg. 2004;30(1):26-32.

27. Camellin M. Laser epithelial keratomileusis for myopia. J Refract Surg. 2003;19(6):666-670.

28. Fong CS. Refractive surgery: the future of perfect vision? Singapore Med J. 2007;48(8):709-719.

29. Litwak S, Zadok D, Garcia-de Quevedo V, Robledo N, Chayet AS. Laser-assisted subepithelial keratectomy versus photorefractive keratectomy for the correction of myopia. A prospective comparative study. J Cataract Refract Surg. 2002;28(8):1330-1333.

30. Rouweyha RM, Chuang AZ, Mitra S, Phillips CB, Yee RW. Laser epithelial keratomileusis for myopia with the autonomous laser. J Refract Surg. 2002;18(3):217-224.

31. Claringbold TV 2nd. Laser-assisted subepithelial keratectomy for the correction of myopia. J Cataract Refract Surg. 2002;28(1):18-22.

32. de Benito-Llopis L, Alió JL, Ortiz D, Teus MA, Artola A. Ten-year follow-up of excimer laser surface ablation for myopia in thin corneas. Am J Ophthalmol. 2009;147(5):768-773.

33. Katsanevaki VJ, Kalyvianaki MI, Kavroulaki DS, Pallikaris IG. Epipolis laser in-situ keratomileusis: an evolving surface ablation procedure for refractive corrections. Curr Opin Ophthalmol. 2006;17(4): 389-393.

34. Whittaker G. Are contact lens associated problems a primary motivational factor for PRK patients? J Br Contact Lens Assoc. 1996;19: 21-23.

35. Walline JJ, Rah MJ, Jones LA. The Children's Overnight Orthokeratology Investigation (COOKI) pilot study. Optom Vis Sci. 2004;81(6): $407-413$.
36. Soni PS, Nguyen T; Overnight Orthokeratology Study Group. Overnight orthokeratology experience with XO material. Eye Contact Lens. 2006; 32(1):39-45.

37. Soni PS, Nguyen TT, Bonanno JA. Overnight orthokeratology: refractive and corneal recovery after discontinuation of reverse-geometry lenses. Eye Contact Lens. 2004;30(4):254-262.

38. Barr JT, Rah MJ, Meyers W, Legerton J. Recovery of refractive error after corneal refractive therapy. Eye Contact Lens. 2004;30(4): 247-251.

39. Berntsen DA, Barr JT, Mitchell GL. The effect of overnight contact lens corneal reshaping on higher-order aberrations and best-corrected visual acuity. Optom Vis Sci. 2005;82(6):490-497.

40. Caroline PF, Andre MP. Fitting corneal reshaping post-LASIK. Contact Lens Spectrum. Apr 2004. Available from: http://www.clspectrum.com/ article.aspx?article=12559. Accessed October 25, 2011.

41. Sorbara L, Fonn D, Simpson T, Lu F, Kort R. Reduction of myopia from corneal refractive therapy. Optom Vis Sci. 2005;82(6):512-518.

42. Hiraoka T, Matsumoto Y, Okamoto F, et al. Corneal higher-order aberrations induced by overnight orthokeratology. Am J Ophthalmol. 2005;139(3):429-436.

43. Watt K, Swarbrick HA. Microbial keratitis in overnight orthokeratology: review of the first 50 cases. Eye Contact Lens. 2005;31(5): 201-208.

44. Wilhelmus KR. Acanthamoeba keratitis during orthokeratology. Cornea. 2005;24(7):864-866.

45. Tseng CH, Fong CF, Chen W, Hou YC, Wang IJ, Hu FR. Overnight orthokeratology-associated microbial keratitis. Cornea. 2005;24(7): 778-782.

46. Hsiao $\mathrm{CH}$, Lin $\mathrm{HC}$, Chen YF, et al. Infectious keratitis related to overnight orthokeratology. Cornea. 2005;24(7):783-788.

47. Yepes N, Lee SB, Hill V, et al. Infectious keratitis after overnight orthokeratology in Canada. Cornea. 2005;24(7):857-860.

48. Araki-Sasaki K, Nishi I, Yonemura N, et al. Characteristics of Pseudomonas corneal infection related to orthokeratology. Cornea. 2005;24(7):861-863.

49. Sun $X$, Zhao $H$, Deng $S$, et al. Infectious keratitis related to orthokeratology. Ophthalmic Physiol Opt. 2006;26(2):133-136.

50. Henriques M, Sousa C, Lira M, et al. Adhesion of Pseudomonas aeruginosa and Staphylococcus epidermidis to silicone-hydrogel contact lenses. Optom Vis Sci. 2006;82(6):446-450.

51. Bruinsma GM, van der Mei HC, Busscher HJ. Bacterial adhesion to surface hydrophilic and hydrophobic contact lenses. Biomaterials. 2001;22(24):3217-3224.

52. Doughty MJ, Aakre BM, Ystenaes AE, Svsrverud E. Short-term adaptation of the human corneal endothelium to continuous wear of silicone hydrogel (lotrafilcon A) contact lenses after daily hydrogel lens wear. Optom Vis Sci. 2005;82(6):473-480.

53. Lipson MJ, Sugar A, Musch DC. Overnight corneal reshaping versus soft disposable contact lenses: vision-related quality-of-life differences from a randomized clinical trial. Optom Vis Sci. 2005;82(10): 886-891.

54. Rah M, Bailey M, Hayes J, et al. Comparison of NEI RQL-42 scores in LASIK vs CRT patients. Invest Ophthalmol Vis Sci. 2004;45:E-Abstract 1578

55. Lee YC, Lim CW, Sam SM, Koh D. The prevalence and pattern of contact lens use in a Singapore community. CLAO J. 2000;26(1): 21-25.

56. Riley C, Chalmers RL. Survey of contact lens-wearing habits and attitudes toward methods of refractive correction: 2002 versus 2004. Optom Vis Sci. 2005;82(6):555-561.

57. Donshik PC. Extended wear contact lenses. Ophthalmol Clin North Am. 2003;16(3):305-309.

58. Schornack MM, Faia LJ, Grienpentrog GJ. Pseudomonas keratitis associated with daily wear of silicone hydrogel contact lenses. Eye Contact Lens. 2008;34(2):124-128.

59. Suchecki JK, Donshik P, Ehlers WH. Contact lens complications. Ophthalmol Clin North Am. 2003;16(3):471-484. 
60. Liu Z, Pflugfelder SC. The effects of long-term contact lens wear on corneal thickness, curvature, and surface regularity. Ophthalmology. 2000;107(1):105-111.

61. Budak K, Hamed AM, Friedman NJ, Koch DD. Preoperative screening of contact lens wearers before refractive surgery. $J$ Cataract Refract Surg. 1999;25(8):1080-1086.

62. Wang X, McCulley JP, Bowman RW, Cavanagh HD. Time to resolution of contact lens-induced corneal warpage prior to refractive surgery. CLAO J. 2002;28(4):169-171.

63. Hartstein J. Corneal warping due to wearing of corneal contact lenses. A report of 12 cases. Am J Ophthalmol. 1965;60(6):1103-1104.

64. Asbell PA, Wasserman D. Contact lens-induced corneal warpage. Int Ophthalmol Clin. 1991;31(2):121-126.

65. Braun DA, Anderson Penno EE. Effect of contact lens wear on central corneal thickness measurements. J Cataract Refract Surg. 2003;29(7): 1319-1322.

66. Nourouzi H, Rajavi J, Okhovatpour MA. Time to resolution of corneal edema after long-term contact lens wear. Am J Ophthalmol. 2006;142(4):671-673.

67. Myrowitz EH, Melia M, O'Brien TP. The relationship between longterm contact lens wear and corneal thickness. CLAO J. 2002;28(4): 217-220.

68. Gupta N, Naroo SA. Factors influencing patient choice of refractive surgery or contact lenses and choice of centre. Cont Lens Anterior Eye. 2006;29(1):17-23.

69. Migneco MK, Pepose JS. Attitudes of successful contact lens wearers towards refractive surgery. J Refract Surg. 1996;12(1):128-133.

70. Salah T, Waring GO 3rd, el Maghraby A, Moadel K, Grimm SB. Excimer laser in situ keratomileusis under a corneal flap for myopia of 2 to 20 diopters. Am J Ophthalmol. 1996;121(2):143-155.

71. Dulaney DD, Barnet RW, Perkins SA, Kezirian GM. Laser in situ keratomileusis for myopia and astigmatism: 6 month results. J Cataract Refract Surg. 1998;24(6):758-764.

72. Buzard KA, Fundingsland BR. Excimer laser assisted in situ keratomileusis for hyperopia. J Cataract Refract Surg. 1999;25(2):197-204.

73. Zadok D, Maskaleris G, Montes M, Shah S, Garcia V, Chayet A. Hyperopic laser in situ keratomileusis with the Nidek EC-5000 excimer laser. Ophthalmology. 2000;107(6):1132-1137.

74. Lindstrom RL, Linebarger EJ, Hardten DR, Houtman DM, Samuelson TW. Early results of hyperopic and astigmatic laser in situ keratomileusis in eyes with secondary hyperopia. Ophthalmology. 2000;107(10):1858-1863.

75. Sakimoto T, Rosenblatt MI, Azar DT. Laser eye surgery for refractive errors. Lancet. 2006;367(9520):1432-1447.

76. Munnerlyn CR, Koons SJ, Marshall J. Photorefractive keratectomy: a technique for laser refractive surgery. J Cataract Refract Surg. 1988; 14(1):46-52.

77. Katsanevaki VJ, Tuft SJ. Refractive surgery: what patients need to know. Br Med Bull. 2007;83:325-339.

78. El-Maghraby A, Salah T, Waring GO 3rd, Klyce S, Ibrahim O. Randomized bilateral comparison of excimer laser in situ keratomileusis and photorefractive keratectomy for 2.50 to 8.00 diopters of myopia. Ophthalmology. 1999;106(3):447-457.

79. Hatch BB, Moshirfar M, Ollerton AJ, Sikder S, Mifflin MD A prospective, contralateral comparison of photorefractive keratectomy (PRK) versus thin-flap LASIK: assessment of visual function. Clin Ophthalmol. 2011;5:451-457.

80. US Food and Drug Administration (2006). Available from: http://www. fda.gov/cdrh/LASIK/lasers.htm. Accessed October 25, 2011.

81. Levinger E, Geyer O, Baltinsky Y, Levinger S. Binocular function and patient satisfaction after monovision induced by laser in situ keratomileusis (lasik). Harefuah. 2006;145(3):186-190, 246-247.

82. Jain S, Ou R, Azar DT. Monovision outcomes in presbyopic individuals after refractive surgery. Ophthalmology. 2001;108(8):1430-1433.

83. Miranda D, Krueger RR. Monovision laser in situ keratomileusis for pre-presbyopic and presbyopic patients. J Refract Surg. 2004;20(4): 325-328.
84. Goldberg DB. Laser in situ keratomileusis monovision. J Cataract Refract Surg. 2001;27(9):1449-1455.

85. Reilly CD, Lee WB, Alvarenga L, Caspar J, Garcia-Ferrer FJ, Mannis MJ. Surgical monovision and monovision reversal in LASIK. Cornea. 2006;25(2):136-138.

86. Garcia-Gonzalez M, Teus MA, Hernandez-Verdejo JL. Visual outcomes of LASIK-induced monovision in myopic patients with presbyopia. Am J Ophthalmol. 2010;150(3):381-386.

87. McGill EC, Erickson P. Sighting dominance and monovision distance binocular fusional ranges. J Am Optom Assoc. 1991;62(10): $738-742$.

88. Tham VM, Maloney RK. Microkeratome complications of laser in situ keratomileusis. Ophthalmology. 2000;107(5):920-924.

89. Moshirfar M, Gardiner JP, Schliesser JA, et al. Laser in situ keratomileusis flap complications using mechanical microkeratome versus femtosecond laser: retrospective comparison. J Cataract Refract Surg. 2010;36(11):1925-1933.

90. Stulting RD, Carr JD, Thompson KP, et al. Complications of laser in situ keratomileusis for the correction of myopia. Ophthalmology. 1999;106(1):13-20.

91. Linebarger EJ, Hardten DR, Lindstrom RL. Diffuse lamellar keratitis: diagnosis and management. J Cataract Refract Surg. 2000;26(7): 1072-1077.

92. Smith RJ, Yadarola MB, Pelizzari MF, Luna JD, Juarez CP, Reviglio VE. Complete bilateral vitreous detachment after LASIK retreatment. J Cataract Refract Surg. 2004;30(6):1382-1384.

93. Luna JD, Artal MN, Reviglio VE, Pelizzari M, Diaz H, Juarez CP. Vitreoretinal alterations following laser in situ keratomileusis: clinical and experimental studies. Graefes Arch Clin Exp Ophthalmol. 2001;239(6):416-423.

94. Mirshahi A, Schopfer D, Gerhardt D, Terzi E, Kasper T, Kohnen T. Incidence of posterior vitreous detachment after laser in situ keratomileusis. Graefes Arch Clin Exp Ophthalmol. 2006;244(2): $149-153$

95. Arevalo JF, Ramirez E, Suarez E, Cortez R, Ramirez G, Yepez JB. Retinal detachment in myopic eyes after laser in situ keratomileusis. $J$ Refract Surg. 2002;18(6):708-714.

96. Arevalo JF, Mendoza AJ, Velez-Vazquez W, et al. Full-thickness macular hole after LASIK for the correction of myopia. Ophthalmology. 2005;112(7):1207-1212.

97. Arevalo JF, Rodriguez FJ, Rosales-Meneses JL, et al. Vitreoretinal surgery for macular hole after laser assisted in situ keratomileusis for the correction of myopia. Br J Ophthalmol. 2005;89(11):1423-1426.

98. Jabbur NS, Sakatani K, O'Brien TP. Survey of complications and recommendations for management in dissatisfied patients seeking a consultation after refractive surgery. J Cataract Refract Surg. 2004;30(9):1867-1874

99. Johnson JD, Azar DT. Surgically induced topographical abnormalities after LASIK: management of central islands, corneal ectasia, decentration, and irregular astigmatism. Curr Opin Ophthalmol. 2001;12(4): 309-313.

100. Fan-Paul NJ, Li J, Miller JS, Florakis GJ. Night vision disturbances after corneal refractive surgery. Surv Ophthalmol. 2002;47(6):533-546.

101. Hersh PS, Steinert RF, Brint SF. Photorefractive keratectomy versus laser in situ keratomileusis; comparison of optical side effects. Summit PRK-LASIK Study Group. Ophthalmology. 2000;107(5):925-933.

102. Condon PI. 2005 ESCRS Ridley Medal Lecture: will keratectasia be a major complication for LASIK in the long term? J Cataract Refract Surg. 2006;32(12):2124-2132

103. Seiler T, Quurke AW. Iatrogenic keratectasia after LASIK in a case of forme fruste keratoconus. J Cataract Refract Surg. 1998;24(7): 1007-1009.

104. Binder PS, Lindstrom RL, Stulting RD, et al. Keratoconus and corneal ectasia after LASIK. J Refract Surg. 2005;21(6):749-752.

105. Randleman JB, Russell B, Ward MA, Thompson KP, Stulting RD. Risk factors and prognosis for corneal ectasia after LASIK. Ophthalmology. 2003;110(2):267-275. 
106. Meghpara B, Nakamura H, Marcai M, et al. Keratectasia after laser in situ keratomileusis: a histopathologic and immunohistochemical study. Arch Ophthalmol. 2008;126(12):1655-1663.

107. Dawson DG, Randleman JB, Grossniklaus HE, et al. Corneal ectasia after excimer laser keratorefractive surgery: histopathology, ultrastructure, and pathophysiology. Ophthalmology. 2008;115(12):2181-2191.

108. Ward MA. Visual rehabilitation with contact lenses after laser in situ keratomileusis. J Refract Surg. 2001;17(4):433-440.

109. Chou B, Wachler BS. Soft contact lenses for irregular astigmatism after laser in situ keratomileusis. J Refract Surg. 2001;17(6):692-695.

110. Ailó JL, Belda JI, Shalaby AM. Correction of irregular astigmatism with excimer laser assisted by sodium hyaluronate. Ophthalmology. 2001;108(7):1246-1260.

111. Dupps WJ Jr, Wilson SE. Biomechanics and wound healing in the cornea. Exp Eye Res. 2006;83(4):709-720.

112. Ortiz D, Piñero D, Shabayek MH, Arnalich-Montiel F, Alió JL. Corneal biomechanical properties in normal, post-laser in situ keratomileusis, and keratoconic eyes. J Cataract Refract Surg. 2007;33(8):1371-1375.

113. Chen MC, Lee N, Bourla N, Hamilton DR. Corneal biomechanical measurements before and after laser in situ keratomileusis. J Cataract Refract Surg. 2008;34(11):1886-1891.

114. Kamiya K, Shimizu K, Ohmoto F. Comparison of the changes in corneal biomechanical properties after photorefractive keratectomy and laser in situ keratomileusis. Cornea. 2009;28(7):765-769.

115. Chen SH, Feng YF, Stojanovic A, Wang QM. Meta-analysis of clinical outcomes comparing surface ablation for correction of myopia with and without 0.02\% mitomycin C. J Refract Surg. 2011;27(7): 530-541.

116. Daoud YJ, Hutchinson A, Wallace DK, Song J, Kim T. Refractive surgery in children: treatment options, outcomes, and controversies. Am J Ophthalmol. 2009;147(4):573-582. e2.

117. Tychsen L. Refractive surgery for special needs children. Arch Ophthalmol. 2009;127(6):810-813.
118. Paysse EA, Coats DK, Hussein MA, Hamill MB, Koch DD. Long-term outcomes of photorefractive keratectomy for anisometropic amblyopia in children. Ophthalmology. 2006;113(2):169-176.

119. Brown SM. Pediatric refractive surgery. Arch Ophthalmol. 2009;127(6): 807-809.

120. Nassaralla BR, Nassarralla JJ Jr. Laser in situ keratomileusis in children 8 to 15 years old. J Refract Surg. 2001;17(5):519-524.

121. O'Keefe M, Nolan L. LASIK surgery in children. Br J Ophthalmol. 2004;88(1):19-21.

122. Phillips CB, Prager TC, McClellan G, Mintz-Hittner HA. Laser in situ keratomileusis for treated anisometropic amblyopia in awake, autofixating pediatric and adolescent patients. J Cataract Refract Surg. 2004;30(12):2522-2528.

123. Waring GO 3rd, Lynn MJ, McDonnel PJ. Results of the prospective evaluation of radial keratotomy (PERK) study 10 years after surgery. Arch Ophthalmol. 1994;112(10):1298-1308.

124. Alió JL, Wolter NV, Piñero DP, et al. Pediatric refractive surgery and its role in the treatment of amblyopia: meta-analysis of the peer-reviewed literature. J Refract Surg. 2011;27(5):364-374.

125. Kidd B, Stark C, McGhee CN. Screening for psychiatric distress and low self-esteem in patients presenting for excimer laser surgery for myopia. J Refract Surg. 1997;13(1):40-44.

126. Illingworth $\mathrm{CD}, \mathrm{Hoh} \mathrm{HB}$, Easty DL. Introduction to laser refractive surgery. In: Claoue C, editor. Laser and Conventional Refractive Surgery. London: BMJ Publishing Group; 1996:1-20.

127. Orr D, Sidiki SS, McGhee CN. Factors that influence patient choice of an excimer laser treatment center. J Cataract Refract Surg. 1998;24(3): 335-340.

128. Montes M, Chayer A, Gomez L, Magallanes R, Robledo N. Laser in situ keratomileusis for myopia of -1.50 to -6.00 diopters. J Refract Surg. 1999;15(2):106-110.

129. Waring GO 3rd. Pediatric refractive surgery review. Arch Ophthalmol. 2009;127(6):814-815
Clinical Optometry

\section{Publish your work in this journal}

Clinical Optometry is an international, peer-reviewed, open access journal publishing original research, basic science, clinical and epidemiological studies, reviews and evaluations on clinical optometry. All aspects of patient care are addressed within the journal as well as the practice of optometry including economic and business analyses. Basic and clinical

\section{Dovepress}

research papers are published that cover all aspects of optics, refraction and its application to the theory and practice of optometry. The manuscript management system is completely online and includes a very quick and fair peer-review system, which is all easy to use. Visit http://www.dovepress. com/testimonials.php to read real quotes from published authors. 